\title{
9 \\ Operational Diversity: Saying What We Mean, Doing What We Say
}

\author{
Wayne Jacobson \\ Jim Borgford-Parnell \\ Katherine Frank \\ Michael Peck \\ Lois Reddick \\ University of Washington
}

Diversity issues, ranging from individual learning styles to institutional equity, are central to teaching and learning, but identifying and addressing these issues is a formidable task. At the Center for Instructional Development and Research (CIDR), our staff is gaining ground on this work through the Inclusive Practices Portfolio, a collaborative forum for documenting, sharing, and supporting our individual and organizational diversity initiatives. The process of developing the center's portfolio and the portfolio itself are mechanisms for change within the center and a model for change at our institution and beyond.

\section{INTRODUCTION}

We often hear that instructors on our campus agree in principle to campus diversity policies, but many remain unsure how to translate these policies into more inclusive classroom practices. Our staff at the Center for Instructional Development and Research (CIDR) have faced a similar dilemma, knowing that diversity issues are central to questions of teaching and learning, but uncertain how to integrate attention to diversity into our work with instructors and administrators in their efforts to improve teaching and learning on campus. In response to these 
parallel dilemmas, CIDR staff began working together to articulate our beliefs about diversity, translate these beliefs into action, and assess the outcomes of our actions. This work has been documented in CIDR's Inclusive Practices Portfolio, which provides us with a central location for integrating our ongoing individual and collaborative efforts. Our experience has demonstrated that a general commitment to diversity and inclusive practices can be transformed into identifiable actions, which in turn provides a basis for assessment, review, and planning for future growth. We also believe this experience provides a framework for others who wish to mobilize around a commitment to diversity.

\section{Challenges and Opportunities OF Diversity AND InClusiveness}

Part of the challenge of addressing diversity is the nature of the topic: $\mathrm{Di}$ versity spans many issues, from individual learning styles to institutional equity, each associated with a wide range of possible actions (Gay, 1994). Much of the campus conversation about diversity has been in terms of recruitment and retention, issues that are only indirectly related to our work as instructional developers. Thus, we found ourselves wondering how to best represent and respond to the complex array of issues included under the umbrella of "diversity," how we fit within the university's broader commitments, and how to prioritize among the many possible actions we could take.

Adding to these challenges is the fact that diversity is a politically charged topic. It is dismissed by some as political correctness; for others, it revolves around a single issue such as racial inequality. Our institution expresses commitment to diversity, but public reaction is mixed: Surveys of state residents show that most want graduates to be able to work effectively in culturally diverse settings, but many are opposed to affirmative action or hiring TAs with accents. Each of these perspectives potentially influences our clients in their work and, therefore, potentially influences how we work with them.

We found it fairly easy to agree about the challenges of addressing diversity, but we were not satisfied to continue leaving the challenges unmet. To paraphrase social activist and educator Myles Horton (1990), we felt we knew the basic reasons for our problems, but we wanted to get further than that. As a result, we began to take intentional steps to expand our knowledge, skills, and understanding of ourselves (Kardia, 1998; Marchesani \& Adams, 1992), and also to articulate our assump- 
tions and document our efforts so that they are subject to review and critical examination (Banks, 1998). Without a singular measure of inclusiveness as a basis for assessing our work, we began assembling our expressed beliefs, records of actions taken, assessments, and reflections into the Inclusive Practices Portfolio. Within the framework of the portfolio, our goal is to "analyze, clarify, and state [our] personal values related to cultural diversity, and to act in ways consistent with [our] beliefs" (Banks \& Banks, 1995, p. 157). Most importantly, the portfolio has helped us work toward this goal both as individuals and as an organization, in order to make it possible to express CIDR's values and assess the consistency of our actions as an organization on our campus.

\section{Organizational Change}

Before the current work on the portfolio, CIDR already had a long history of involvement with diversity issues on our campus. CIDR produced a widely used video on the topic, Teaching in the Diverse Classroom, sponsored campus-wide forums and guest speakers, and collaborated with campus-wide diversity initiatives. Furthermore, in our work with individual instructors we have had numerous opportunities to raise questions related to diversity among their students and its implications for their teaching. However, in spite of this long history and shared commitment to diversity, we found that as a group we were not necessarily thinking about diversity in the same ways or systematically assessing our work in the area. As the make-up of our staff changed over time, we did not have the same experiences to provide common reference points as a basis for shared values and collaborative actions. We also discovered we were not consistent in our decisions about bringing diversity issues into consulting. CIDR's goal already focuses on better learning for all students (Banks, 1993), but should we proactively raise diversity issues, only respond to instructors' explicit questions about diversity, or speak in terms of better learning for all students even when instructors explicitly ask questions about student diversity?

Prompted by these questions, we began very simply with a conversation in a staff meeting about the implications of diversity on our work with clients. This seemingly straightforward process led us to the realization that our individual experiences and knowledge of diversity issues had provided us with a diverse range of insights on what we could do. However, this collection of interrelated ideas was difficult to encompass within a single shared vision for CIDR's role on campus. We wanted to 
collaboratively articulate this vision, building on the strengths of our diverse individual interests and experiences related to addressing the challenges and opportunities of diversity on our campus, but we were also wary of the exclusionary processes that often accompany group effort. Senge defines this unfortunately common group process as an organizational learning disability whereby "joint decisions are watered-down compromises reflecting what everyone can live with, or else one person's view foisted on the group" (1990, p. 24). We wanted our collective activities to be based upon a fundamental recognition of our own diversity, and as such to become the nexus for sharing, improving, and supporting our individual endeavors.

As we sought to implement this organizational change, it became very important to identify and acknowledge the organizational structure and culture of our center so that the process we had embarked upon would not only reflect and affirm that organization, but would also illuminate areas for change. This notion is congruent with much of the diversity, multicultural education, and organizational change literature, which argues for both institutions and individuals to begin their work in this arena by first examining themselves (Gay, 2000; Gillespie, 2000; Kardia, 1998; Laylock, 2000; Marchesani \& Adams, 1992; Senge, 1990; Watkins \& Marsick, 1993).

The underlying organizational framework of CIDR draws heavily upon a Total Quality Management (TQM) model that empowers individuals to work within and across teams to address and manage our daily activities. We are guided by five basic principles in particular that were drawn from Warren Deming's (1986) work in this area: 1) client orientation, 2) continuous improvement, 3) empowerment of our staff, 4) teamwork, and 5) professional development. In some ways this organizational identity positions us well to pursue change, but it also posed obstacles. For example, in one of our first conversations on diversity we found ourselves struggling to align the principle of client orientation, which often requires a responsive stance, with a desire to take on a more proactive role initiating change with our clients.

Our organization employs several of the structural elements and values of a TQM model, but the culture of our center more closely resembles that of a learning organization. In learning organizations, "learning takes place in individuals, teams, the organization, and even the communities with which the organization interacts.... Learning results in changes in knowledge, beliefs, and behaviors" (Watkins \& Marsick, 1993, p. 8). Continuous learning on all levels serves CIDR staff and the cam- 
pus community well, and is generally manifested in workshops, peer observations, and literature exchanges. However, few topics are as broad reaching, multi-layered, and personally challenging as diversity, and it remained a challenge for us to intentionally pursue organizational change over and above the learning of individuals and working groups within the organization. It was for this reason that the Inclusive Practices Portfolio was developed as an important orienting point for our efforts: providing a forum for documenting the complexity of the topic (diversity) and the task (collaborative learning to promote organizational change), and doing so within CIDR's normal practices of data collection, analysis, and reflection (Nyquist \& Wulff, 1988).

\section{Saying What We Mean}

The cornerstone of the portfolio is a diversity statement, developed through a series of interactions with one another, the diversity literature, and other members of the campus community. This statement attempts to make explicit the implicit assumptions guiding our practices (Rando \& Menges, 1991). Our drafting of the statement began with a challenge by Professor Geneva Gay of the Center for Multicultural Education at the University of Washington, to define our roles on campus with respect to diversity, and to determine the actions we were uniquely situated to take in those roles. This challenge helped us start in two ways: First, rather than trying to develop a comprehensive statement about diversity in higher education, we were encouraged to focus on the role our organization might be able to play on our campus. Second, it focused us on the actions implied by the principles we were trying to articulate.

In response to this challenge, staff members worked in groups to articulate or map out our organization's central roles on campus with respect to diversity. Groups presented their work to one another, and an editing group worked with the notes and concept maps to draft a statement which attempted to distill the work from each group into a single document. This draft was circulated among the staff for feedback and went through numerous revisions until staff agreed that it represented our organization's roles on campus.

Groups of staff members were then asked to draft a set of action statements implied by these roles. The action statements similarly went through numerous revisions and led us back to revise the diversity statement itself as we faced the challenges of putting the earlier draft into action. The process of articulating our principles and actions spanned a 12- 
month period, ending with a staff consensus that it adequately represented the values and priorities of our work on campus, and also with the understanding that the document was still open for further development. A current draft of the statement is provided in Appendix 9.1.

\section{Doing What We Say}

After coming to a consensus on the statement of principles and actions, we further developed the action statements using the Standard Practices Survey. Staff members were asked to indicate for each action statement 1) the extent to which it is part of their typical consulting practice, and 2) the extent to which they think it should be part of their typical consulting practice. Sample items showing the format of the instrument are provided in Appendix 9.2.

Survey responses indicated that staff's consulting practices were most consistent (that is, ratings for "is" most closely matched ratings for "should be") for items directly related to exploring immediate classroom contexts and teaching practices (for example, items $l$ and $f$ ). Practices were least consistent for items that implied working collaboratively with individuals or offices outside of CIDR (for example, items $r$ and $q$ ). The next least consistent practices were for items most explicitly related to diversity and inclusiveness (for example, items $a$ and $b$ ). Figure 9.1 represents the results of the survey for our consulting staff.

FIGURE 9.1

Standard Practices Survey Results Typical Consulting Practices: "Is" versus "Should Be"

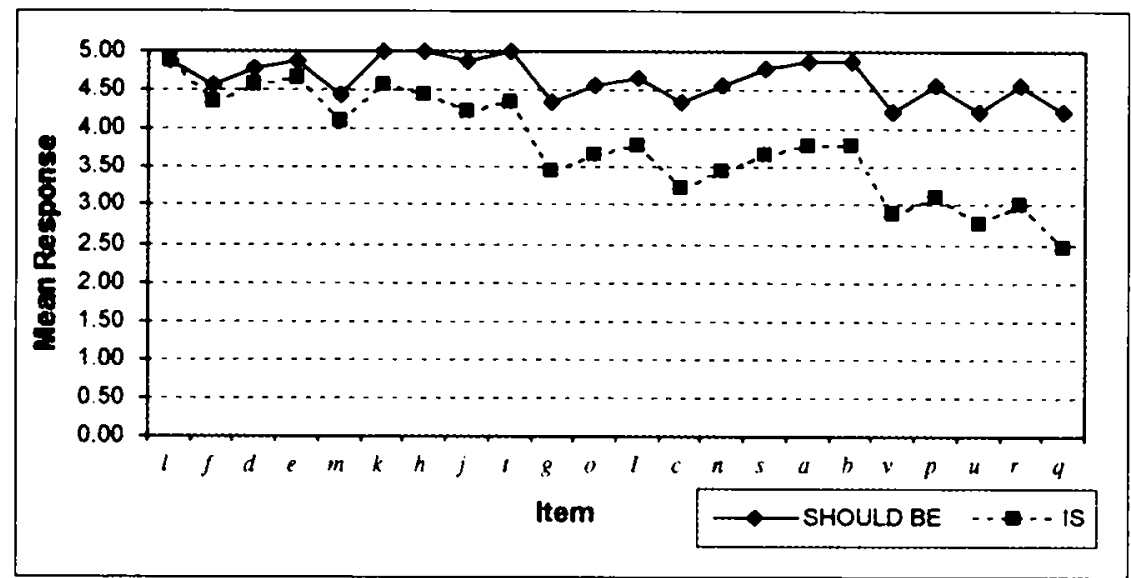


The survey results provided us with important information about our consulting practices, which we used in three ways. First, we revisited the original statement and discussed possible revisions. For example, do all staff members need to take time to stay informed about university policies and departmental changes, or is it sufficient for CIDR leadership to keep informed and pass information along as needed? Second, in our discussion of the survey results we discovered areas that we unintentionally neglected in our draft statement: 1) explicit attention to faculty diversity and identity development (in addition to diversity among students), and 2) as part of our beliefs about how change takes place, explicit attention to ongoing follow-up with clients and encouraging them to share their experiences with colleagues.

Third, and most important, we used this information to help us start examining our practices and identify areas in which we need to put our commitments into practice more effectively. Based on the survey results, staff members were asked to select a professional development activity designed with the specific goal of examining attention to diversity in our consulting practices. Examples of professional development activities included maintaining a journal of interactions with clients, taping consultation sessions, inviting colleagues to observe consultations, and presenting cases for peer review (see Appendix 9.3). Reports and reflections on these experiences were documented and added to the Inclusive Practices Portfolio for others to review.

Following these activities, staff will review the diversity statement and re-take the Standard Practices Survey. Individuals can target specific areas for continuing development by referring to colleagues' records in the Inclusive Practices Portfolio in order to see who has worked in that area previously and who might be interested in additional collaboration. We will also make plans for external review, asking others in the campus community to assess our portfolio, and asking our clients to provide feedback on their experience working with our staff on issues of diversity.

\section{EFFECTS}

As we have taken steps to articulate our goals and assess our actions, with respect to diversity on campus, we have also been mindful of the overarching question that originally prompted us to take these initiatives: As instructional developers, how can we contribute to wider campus efforts to foster a more inclusive teaching and learning community? Our efforts 
have helped us as a group to become more mindful of the gap between our personal and organizational values and the even larger gap between our beliefs and our actions, but how has this work affected the larger community we are a part of?

Our most direct effect to the campus is through consulting services to individuals and departments. Our work with the Inclusive Practices Portfolio has raised individual staff members' level of attention to diversity issues, and they report changes in the questions which they ask and issues which they raise as a result of our paying attention to these issues. It has also contributed to our development of materials, workshops, and Internet resources that we provide for the campus. We will continue to document staff members' reports of changes in their consulting, client feedback, and other professional development activities that allow us to examine and improve our consulting and its impact on campus. Our hope is that through these ongoing processes of documentation, reflection, and development, the portfolio will continue to evolve as a record of our collective best practices and improvement over time.

Another effect of our work has been to demonstrate the possibility of change. Since our work was reported in our university's staff newspaper and on our center's web site, we have received feedback from the campus community and have also been approached by others to assist them in the process of instituting similar changes. With a more specifically articulated statement of our own roles on campus, we are also better prepared to collaborate with other units in broader institutional initiatives. Finally, our own experience with the complexity of this process has also given us a greater appreciation of what it would take for departments to go through a similar process.

The Inclusive Practices Portfolio provides a structure for ongoing critical self-examination. Noffke (1995) describes this action research process as one in which

Understandings and actions emerge in a constant cycle, one that highlights the ways in which educators are partially correct, yet in continual need of revision, in their thoughts and actions. The process does not end, as with traditional notions of research, with richer understandings of education for others to implement; rather, it aids in an ongoing process of identifying contradictions, which in turn, help to locate spaces for ethically defensible, politically strategic actions. (p. 4) 
Like the process Noffke describes, our work with the Inclusive Practices Portfolio is not expected to reach a definitive end. Collaboratively documenting and reflecting on our practices is helping us locate spaces for our center to take action, assess outcomes of the actions we are uniquely situated to take, and position ourselves for ongoing active participation in our university's diversity initiatives.

\section{REFERENCES}

Banks, C. A. M., \& Banks, J. A. (1995). Equity pedagogy: An essential component of multicultural education. Theory into Practice, 34 (3), 152-158.

Banks, J. A. (1993). Multicultural education: Development, dimensions, and challenges. Pbi Delta Kappan, 75 (1), 22-28.

Banks, J. A. (1998). The lives and values of researchers: Implications for educating citizens in a multicultural society. Educational Researcher, 27 (7), 4-17.

Center for Instructional Development and Research (Producer). (1991). Teaching in the Diverse Classroom [Video]. (Available from Anker Publishing Company, Inc., P. O. Box 249, Bolton, MA 01740-0249 or www.ankerpub.com)

Deming, W. E. (1986). Out of the crisis. Cambridge, MA: Massachusetts Institute of Technology.

Gay, G. (1994). A synthesis of scholarship in multicultural education: Urban monograph series. Oak Brook, IL: North Central Regional Educational Laboratory.

Gay, G. (2000). Culturally responsive teaching. New York, NY: Teachers College Press.

Gillespie, K. H. (2000). The challenge and test of our values: An essay of collective experience. In M. Kaplan \& D. Lieberman (Eds.), To improve the academy: Vol. 18. Resources for faculty, instructional, and organizational development (pp. 27-37). Bolton, MA: Anker.

Horton, M. (1990). The long haul. New York, NY: Doubleday.

Kardia, D. (1998). Becoming a multicultural faculty developer: Reflections from the field. In D. DeZure \& M. Kaplan (Eds.), To improve the academy: Vol. 17. Resources for faculty, instructional, and organizational development (pp. 15-33). Stillwater, OK: New Forums Press.

Laylock, M. (2000). QILT: An approach to faculty development and institutional self-improvement. In M. Kaplan \& D. Lieberman (Eds.), To improve the academy: Vol. 18. Resources for faculty, instructional, and organizational development (pp. 69-82). Bolton, MA: Anker. 
Marchesani, L., \& Adams, M. (1992). Dynamics of diversity in the teachinglearning process. New Directions in Teaching and Learning, No. 52. San Francisco, CA: Jossey-Bass.

Noffke, S. (1995). Action research and democratic schooling: Problematics and potentials. In S. Noffke \& R. Stevenson (Eds.), Educational action research: Becoming practically critical (pp. 1-10). New York, NY: Teachers College Press.

Nyquist, J., \& Wulff, W. (1988). Consultation using a research perspective. In $\mathrm{E}$. C. Wadsworth (Ed.), A handbook for new practitioners (pp. 82-88). Stillwater, OK: New Forums Press.

Rando, W., \& Menges, R. (1991). How practice is shaped by personal theories. New Directions for Teaching and Learning, No. 45. San Francisco, CA: JosseyBass.

Senge, P. (1990). The fifth discipline. New York, NY: Currency Doubleday.

Watkins, K. E., \& Marsick, V. J. (1993). Sculpting the learning organization. San Francisco, CA: Jossey-Bass.

Contact all authors at:

College of Education

University of Washington

122414 th NW

Seattle, WA 98177

(206) 543-6588

(206) 685-1213 (Fax)

Email: jacobson@cidr.washington.edu

bparnell@u.washington.edu

kfrank@u.washington.edu

mpeck@u.washington.edu

redl@u.washington.edu

Wayne Jacobson is Interim Assistant Director of the Center for Instructional Development and Research (CIDR) at the University of Washington.

Jim Borgford-Parnell is a staff consultant at the Center for Instructional Development and Research (CIDR). He has a master's degree in Adult Education and has been teaching at the postsecondary level for 21 years. He is currently a PhD student in Educational Leadership and Policy Studies at the University of Washington, and also teaches education courses in the master's program at Antioch University. 
Katherine Frank is a staff consultant at the Center for Instructional Development and Research (CIDR). Starting in August 2001, she will be an Assistant Professor of English and Codirector of the Writing Program at the University of Southern Colorado.

Michael Peck is a staff consultant at the Center for Instructional Development and Research (CIDR). He holds master's degrees in Social Work and in Jewish Communal Service and has clinical practice experience in family service and healthcare settings. Currently, he is completing his $\mathrm{PhD}$ in Social Welfare at the University of Washington School of Social Work.

Lois Reddick is a staff consultant at the Center for Instructional Development and Research (CIDR) and a graduate student in Multicultural Education at the University of Washington. 


\section{APpendix 9.1 \\ Current Draft of the CIDR Diversity Statement}

\section{Diversity and Inclusiveness in our work as Instructional Development Consultants at CIDR}

In every class, there are students who differ from the instructor and from one another in ways that profoundly affect how they experience classroom activities and how they learn. Factors of identity (such as gender, race, and ethnicity) are interwoven with individual differences (such as ability and experience with the subject matter) and these work together to affect how students relate to the instructor, to one another, and to the subject matter. Our role as instructional consultants is to help instructors teach in ways that optimize learning opportunities for all their students.

Our work with diversity and inclusiveness is informed by our knowledge of faculty and student roles, relationships and interactions, by our understanding of how learning and change take place, by goals and policies of the university, and by our recognition of diversity's larger historical, political, and social contexts. In practical terms, however, this work begins with a client's request for consultation regarding his or her immediate situation.

To put this vision into practice, consultants:

\section{- Identify the specific contexts for teaching and learning.}

Classroom practices are shaped by factors that are rarely visible in the classroom; for example, instructors' and students' academic and personal backgrounds, current developments in the department and in the discipline, and the history and priorities of the institution. One goal of consultation is to make these influences visible so that they become open to question, analysis, and reconsideration.

- Encourage the successful management of the challenges related to diversity.

Our ultimate goal to help clients see the diversity that students bring to the classroom as a contribution to better teaching and learning, rather than as an obstacle to it. However, many clients who come to us are uncomfortable addressing issues of diversity, often due to the perceived magnitude and complexity of the task or the fear of being judged for their actions.

Because these feelings might inhibit clients from taking action, we try to make the consulting relationship a safe, non-threatening set- 
ting for considering change. Our immediate goal is to help clients identify areas where they can begin to take action.

\section{- Motivate and model processes of change.}

We try to motivate clients by helping them see how strategic choices can lead to meaningful change in their immediate situations. We do not want to disregard or minimize a client's apparent reluctance to discuss sensitive or politically charged topics, and we acknowledge the challenges they are facing.

Change is slow, incremental, and uneven. From the beginning, we want to honor clients' concerns, experiences, and efforts they are already making to teach effectively. Utilizing a variety of information sources, we present them with opportunities to see their situations from other perspectives and with resources that provide strategies and models for change.

In order to help clients think through and negotiate the process of change, consultants:

\section{Ask questions about:}

a) Contributions that students make to the way the course is taught, based on the different backgrounds, identities, and perspectives that they bring to it

b) Ways in which the instructor is accounting for student diversity in his or her planning and teaching; for example, varieties of learning styles, life experiences, amount of experience with the subject matter, goals for taking the course, expectations of classmates

c) Previous experiences and assumptions the client has related to student diversity (see $a \& b$, above)

d) Challenges of the teaching situation in terms of class size, preceding and following courses, students' backgrounds and ability levels; for example, is the course required or elective, for majors or non-majors, novice or experienced learners?

e) Previous experiences the client has had in this type of teaching situation

f) What the client likes / doesn't like about this teaching situation 
g) How the course is taught by, and valued by, others in the department

h) What motivates the client to request assistance or consider change at this time

i) Previous experiences the client has had with making or assessing changes in his or her teaching

j) Limitations on the changes that can be made to a course because of the shared responsibilities for change (with students, other instructors, etc.) and variables not under the client's control

\section{Create opportunities to:}

k) Help the client value and view the course from the students' perspective via student feedback, relevant research, or other data

1) Expand the client's range of options for approaches to teaching

m) Express our own experiences dealing with challenges / change

n) Provide models of ways to interact positively and productively around potentially controversial issues, in order to help clients learn to have these kinds of interactions with their students

o) Learn ourselves through means we might suggest to our clients; for example, through reflection, documentation, or peer review of our work

\section{Keep ourselves informed about:}

p) University policies regarding departmental program reviews, strategic planning, curriculum transformation, admissions, and retention

q) Departments undergoing changes related to courses offered and student opportunities

r) What other instructors, programs, or institutions, as well as our CIDR colleagues, are doing to address diversity and inclusiveness

s) Theories of learning, change, and identity development, concerning both clients and their students 
Work collaboratively with:

t) Colleagues and peers within and outside CIDR (always remembering to protect client confidentiality)

u) Departmental leaders, advisors, or coordinators in positions to initiate or advocate change

v) Other units on campus; for example, the Curriculum Transformation Project, the Office of Educational Opportunity Program, Graduate Opportunities and Minority Achievement Program

Follow up with clients to:

w) Find out how designs or strategies we've developed are working

$\mathrm{x})$ Request permission to share their designs or strategies with other clients 


\section{APPENDIX 9.2 \\ CIDR Standard Practices Survey}

We developed this survey as the next step for building on our work with the CIDR diversity statement. The items on the survey are taken directly from the actions that are identified on the statement.

\section{Survey Goals}

The survey asks us to identify what we typically talk about when we are consulting, and also asks us to identify what we think we should typically talk about. The goals of the survey are to help us each find out what colleagues are doing, and to help us determine together areas in which we want to develop in our consulting.

\section{Confidentiality}

You will see that the survey gives you the option of remaining anonymous. No one will trace responses to the individual who made them, and no individual's survey responses will be singled out for presentation apart from the rest.

\section{Feedback}

There is space on the survey to comment on the survey itself and on the experience of filling it out, and there is also space to suggest additional items if you think they should be brought up for everyone to discuss. In part, we are assessing how well we are implementing the diversity statement, and in part we are assessing how well the diversity statement really captures what we think we should be doing. Please add your comments and suggestions to the survey document or email them directly to Wayne.

\section{Real World Consultations}

Finally, when you are answering the parts of the survey that address what we should be doing, think about the real world, rather than an ideal one. That is, ideally it would be nice to ask all these questions (and many more) so that our consulting is based on the most thorough exploration of issues possible. In the real world, however, time is limited, and so is our clients' patience to answer all the questions we might want to ask. To say that something is not a typical topic area in your consulting is not to say it's unimportant, but simply that it isn't necessary to bring it up with each and every client.

\section{Thanks}

Thanks for your participation. If you have questions about the survey or the process of filling it out, ask Wayne or Katherine. 


\section{Standard Practices Survey}

For each question or topic area (Part 1) and each activity (Part 2), please indicate the extent to which it is part of your consulting. Please respond to each item twice. In the shaded column indicate the extent to which that item IS your typical practice in consulting. In the other column indicate the extent to which you think the item SHOULD BE a typical practice in our consulting.

Notice that " 5 " does not indicate that the item is better or more important, although it does suggest that the item occurs more frequently. Use " 2 " and " 4 " for items that fall somewhere between the others.

$1=$ Not Likely $-\mathrm{I}$ rarely, if ever, bring this up in the course of consulting.

2

$3=$ It Depends - I follow this line of questioning if it seems relevant to the immediate situation.

\section{4}

$\mathbf{5}=$ Typical Practice $-I$ almost always bring this up in consulting, whether the client does or not.

\section{Part1 Question or Topic Area}

a. Contributions that students make to the way the course is taught, based on the different backgrounds, identities, and perspectives that they bring to it

b. Ways in which the instructor is accounting for student diversity in his or her planning and teaching; for example, varieties of learning styles, life experiences, amount of experience with the subject matter, goals for taking the course, expectations of classmates

c. Previous experiences and assumptions the client has related to student diversity (see a $\&$ b, above)

d. Challenges of the teaching situation in terms of class size, preceding and following courses, students' backgrounds and ability levels: for example, is the course required or elective, for majors or non-majors, novice or experienced learners?

e. Previous experiences the client has had in this type of teaching situation

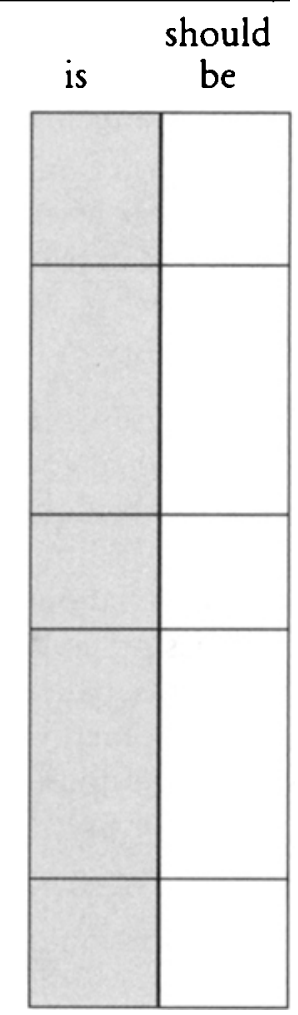


f. What the client likes / doesn't like about this teaching situation

g. How the course is taught by, and valued by, others in the department

h. What motivates the client to request assistance or consider change at this point in time

i. Previous experiences the client has had with making or assessing changes in his or her teaching

j. Limitations on the changes that can be made to a course because of the shared responsibilities for change (with students, other instructors, etc.) and variables not under the client's control

k. Ways to help the client value and view the course from the students' perspective via student feedback, relevant research, or other data

1. Ways to expand the client's range of options for approaches to teaching

$m$. Ways to express our own experiences dealing with challenges / change

n. Models of ways to interact positively and productively around potentially difficult or controversial issues, in order to help clients learn to have these kinds of interactions with their students

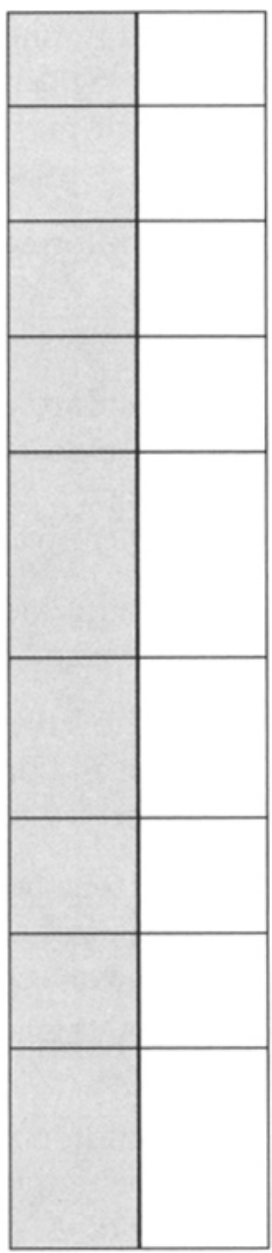

$1=$ Not Likely-I rarely, if ever, do this.

2

$3=$ It Depends - I do this when it seems relevant.

4

5 = Typical Practice-I almost always do this, whether it affects a specific client or not.

Part 2 Activity

o. Learn ourselves through means we might suggest to our clients; for example, through reflection, documentation, or peer review of our work

should

\begin{tabular}{|l|l|} 
is & be \\
\hline & \\
& \\
\hline
\end{tabular}


p. Keep informed about university policies regarding departmental program reviews, strategic planning, curriculum transformation, admissions, and retention

q. Keep informed about departments undergoing changes related to courses offered and student opportunities

r. Keep informed about what other instructors, programs, or institutions, as well as our CIDR colleagues, are doing to address diversity and inclusiveness

s. Keep informed about theories of learning and change

t. Work together with colleagues and peers within and outside CIDR (always remembering to protect client confidentiality)

u. Work together with departmental leaders, advisors, or coordinators in positions to initiate or advocate change

v. Work together with other units on campus

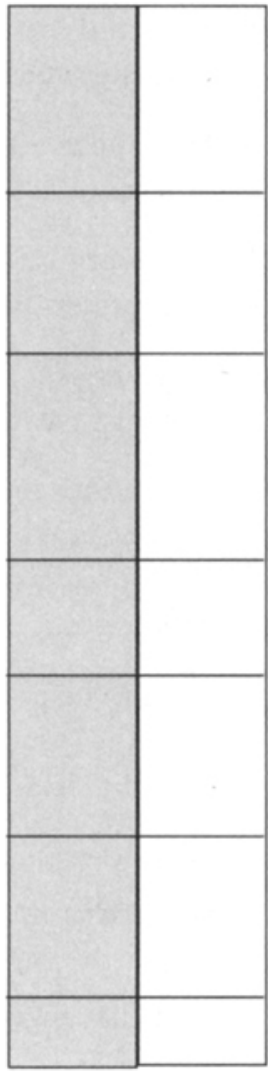

\section{Additional Items}

Use this section to identify additional items that you would like to offer to the rest of the staff for discussion. As you did in the previous sections, respond to each item twice. In the shaded column indicate the extent to which that item IS your typical practice in consulting. In the other column indicate the extent to which you think the item SHOULD BE a typical practice in our consulting.

$1=$ Not Likely-I rarely, if ever, do this.

2

$3=$ It Depends-I do this when it seems relevant.

4

5 = Typical Practice - I almost always do this, whether it affects a specific client or not. 


\section{Part 3 Additional Items}

(add as many rowes to the table as you need)

w.

$\mathbf{x}$.

y.

Z.

\section{Comments}

Do you have any additional comments on the survey items, survey construction, or the experience of filling it out? (use as much space as you need)

Name (optional):

Your name will not be included in any report of the compiled results. However, if you provide your name, then it will be possible to follow up with you regarding additional items that you suggested or comments that you made. You can also send your additional items and comments by email if you would like a response but you don't want to include them with this survey. 


\section{APPENDIX 9.3 \\ CIDR Staff Development Options}

The outcomes of our Standard Practices Survey suggest that as a group, we'd like to be doing more to incorporate attention to diversity into our consulting practice. In order to help us work toward this goal during fall quarter, please select an independent professional development activity, on your own or in collaboration with others. Here's a brainstormed list of possible activities:

(a) write up one or more cases with explicit attention to the role of diversity and how it was addressed in the consulting process (for example, using Michael's case presentation form)

(b) select some reading material (or a lecture, video series, etc.) which will help you improve your consulting in relation to diversity and inclusiveness

(c) select an individual to interview or interact with during the quarter (for example, someone from the Curriculum Transformation Project, GO-MAP, or Multicultural Education) in order to help you develop your consulting skills in relation to diversity and inclusiveness

(d) participate in an internet discussion list on issues of diversity, or raise diversity-related questions on another list that you typically participate in

(e) keep a consulting journal reflecting on your interactions with clients; review and reflect on how diversity was addressed (or not) in the consulting process

(f) record (on audiotape or videotape) your interactions with a client; review and reflect on how diversity was addressed (or not) in the consulting process

(g) work on a case collaboratively (co-consulting or peer observation of your consulting); meet with colleagues to discuss how diversity was addressed (or not) in the consulting process

(h) work with colleagues to role play handling particular case situations; meet with colleagues to discuss how diversity was addressed (or not) in the consulting process 
(i) develop a consulting portfolio providing evidence of how your consulting practices incorporate attention to diversity and inclusiveness

These suggestions are just to get you started. Feel free to propose something else if it will be more useful for you. Whatever you choose, make a decision by September 15 so that it doesn't get put off until the quarter becomes less busy in late November. I'd like to post a list of everyone's choices so that you can have the chance to interact with people about their projects during the quarter if you like.

On our next Staff Day (January 3), be prepared to present a brief reflection on what you did and what you learned from it. The purpose is not to provide a comprehensive presentation of everything you did, but to give colleagues a sense of what they might learn by trying something similar in the future. 